\title{
Species relationships in Chenopodium quinoa and Chenopodium album on the basis of morphology and SDS-PAGE profiles of soluble seed proteins
}

\author{
Rajkumari Jashmi Devi, Nikhil K Chrungoo* \\ Department of Botany, Centre for Advanced Studies, North-Eastern Hill University, Shillong, India.
}

\section{ARTICLE INFO}

Article history:

Received on: 13/11/2015

Revised on: 06/12/2015

Accepted on: 14/12/2015

Available online: 19/12/2015

Key words:

Chenopodium quinoa, $C$.

album, SDS-PAGE, soluble

seed protein

\begin{abstract}
Nineteen accessions of Chenopodium, comprising of 11 accessions of C. quinoa and 8 accessions of C. album were evaluated. Morphological variations were observed in leaf colour, shape and margins, type of pollen grains, seed colour, seed coat texture and morphology of seed edges amongst the accessions. SDS-PAGE profiling of soluble seed proteins revealed 22 bands ranging in molecular mass from 26-68 kDa. While 6 protein bands were monomorphic, 16 protein bands were polymorphic. One band representing protein with molecular mass of 35.76 $\mathrm{kDa}$ was detected only in the accession IC-341704 of C. album. Five exotic accessions viz. EC-507744, EC507742, EC-507738, EC-5077391 and EC-507741, belonging to C. quinoa, showed the presence of a duplex of 33.55 and $29.59 \mathrm{kDa}$ bands which was not detected in any other accession. The dendrogram generated from the scoring profiles of SDS-PAGE of soluble seed proteins segregated the accession as per their taxonomic classification into $C$. quinoa and $C$. album. While the accessions belonging to $C$. album showed a high degree of morphological heterogeneity, the SDS-PAGE profiles of seed proteins indicated low level of variations within the accessions of each species. Further, the accessions IC-411824 and IC-411825 showed more closeness with $C$. quinoa than C. album.
\end{abstract}

\section{INTRODUCTION}

The genus Chenopodium of Amaranthaceae family comprises about 150 species [1]. The domesticated species of Chenopodium viz. C. quinoa, C. berlandieri subsp. nuttalliae, C. pallidicaule, $C$. album, and $C$. giganteum, are important as grain crops as well as forage and leafy vegetable. While the leaves of $C$. album are known to be a good source of vitamins and micronutrients [2], C. quinoa is important for gluten free flour and high protein content of its grains $[3,4]$. While $C$. quinoa $(2 \mathrm{n}=4 \mathrm{x}=36)$ is reported as tetraploid of putative allopolyploid origin, C. album is known as a complex of diploid $(2 \mathrm{n}=18)$, tetraploid $(2 n=36)$ or hexaploid $(2 n=54)$ species with endopolyploidy and autopolyploidy as the origin of polyploidy $[5,6,7]$. Chenopodium has been one of the most taxonomically difficult representatives of the family Chenopodiaceae. While Fuentes-Bazan et al. [8] have clearly described the paraphyletic

* Corresponding Author

Nikhil K. Chrungoo, Department of Botany, North Eastern Hill

University, Shillong- 793022, India. mobile: (+91)9436101651;

tel: (+ 91) 36427 22211; fax: (+91) 36425 50076;

Email: nchrungoo@nehu.ac.in nature of the genus on the basis of morphological and molecular data, a clear set of carpological characters, especially the fruit/seed anatomy, for resolving taxonomic issues in the genus are yet to be evolved. The domesticated species of Chenopodium are divided into two subsections on the basis of pericarp and perianth morphology and crossing relationships [9]. The first subsection Cellulata contains allotetraploids $(2 n=4 x=36)$ like $C$. quinoa and C. berlandieri subsp. nuttaliae. The second subsection Leiosperma includes domesticated and semi-domesticated forms like $C$. pallidicaule $(2 n=18)$ and C. album $(2 n=18,36,54)[10,11]$. While most of the work on genetic diversity and phylogeny in Chenopodium has focused on domesticated species like C. quinoa and $C$. berlandieri subsp. nuttalliae $[11,12,13,14,15]$, very few studies have been undertaken on important weed species like $C$. album, C. berlandieri, C. ficifolium, C. glaucum, C. murale and C. strictum.

Previous studies aimed at elucidating this taxonomic complex on the basis of cytology [16,17], karyotypic analysis [6,7], flavonoids [18], RAPD profiles [11,13,19], ISSR markers [20], directed amplification of minisatellite DNA (DAMDA) [13], microsatellite markers [14], ribosomal DNA [15] clearly indicate the existence of $C$. album as the most polymorphic plant species of 
genus Chenopodium. While some authors have recognized numerous segregate intergrading species in C. album, others have developed elaborate intra-specific hierarchies with numerous subspecies, varieties, forms, and even sub-forms [21]. Neither approach has, however, brought satisfactory and uncontroversial results. This lack of solid knowledge about the Chenopodium species has led to the need for a set of appropriate markers for proper identification of various species in this genus. Partap and Kapoor [22] have grouped the Himalayan C. album into four cultivars with black, brown, red and white seeds.

The high degree of heterogeneity at morphological, cytological and molecular levels $[2,6,13]$ clearly indicates that $C$. album in India is an aggregate taxon, thereby raising a question mark on the identity of accessions belonging to this species.

\section{MATERIALS AND METHODS}

\subsection{Materials}

Seeds of nineteen accessions of the genus Chenopodium, comprising of 11 accessions of $C$. quinoa and 8 accessions of $C$. album (Table 1), studied in the present investigation, were procured from National Bureau of Plant genetic resources, NBPGR, India. Plants of each accession were raised to maturity in the experimental fields of North Eastern Hill University, Shillong.

\subsection{Morphology}

Each accession was evaluated for various morphological parameters including colour, shape and arrangement of leaves, flower color, pollen morphology, colour, shape and surface features of seeds. Data was collected for two successive years with three replications for each accession. Seed coat morphology was determined by scanning electron microscopy after removal of the pericarp from the seeds and sputter-coating with Gold-platinum using FINE COAT 10N sputter JFC-1100. Scanning electron microscopy of pollen grains was carried out after fixing entire flowers with $3 \%$ glutaraldehyde for 4 hours followed by washing with phosphate buffer and dehydration by passing through a series of increasing concentrations (30 to 100\%) of acetone at $4^{\circ} \mathrm{C}$

\subsection{SDS PAGE}

Soluble seed proteins were extracted from mature and healthy seeds of each accession using $20 \mathrm{mM}$ Tris-Cl extraction buffer ( $\mathrm{pH}$ 8.0) containing 2mM EDTA and 1mM PMSF. Protein concentration in each sample was determined according to Bradford [23]. SDS-PAGE of the extracted seed protein was carried out on $15 \%$ polyacrylamide gel following the method of Laemmli [24]. The electrophoretic profile of seed proteins of each accession was recorded as presence (1) or absence (0) of a band of a particular molecular weight. The Jaccard's similarity coefficient between different accessions was derived from the binary data showing the pair wise similarity between the accessions.

\section{RESULTS AND DISCUSSION}

While the accessions of Chenopodium investigated in the study did not show any variations in flower colour, leaf arrangement and seed shape they showed variations in colour, shape and margins of leaves, colour and texture of seed coat, seed edge morphology and type of pollen grains (Table 1). Even though Bhargava et al. [25] have reported intra-specific variations in certain phenotypic traits including plant height, days to flowering, days to maturity, leaf area, seed size, inflorescence length, dry weight per plant amongst accessions of $C$. quinoa, our results do not reveal any variations in any of the qualitative morphological characters amongst different accessions of $C$. quinoa studied in the present investigation. On the other hand, C. album showed morphological heterogeneity with green/ reddish leaves, black/ brown/ white seeds, smooth/ reticulate seed coat with smooth as well as patterned edges.

Except for the accessions IC-341704 and IC-341700, which had reticulated seed surface, all other accessions of Chenopodium investigated in the present study had a smooth and finely lineated seed surface. This is in contrast with the observations of Karcz [26], who have observed reticulate and flatly tuberculate type seed surfaces in $C$. berlandieri and $C$. quinoa and smooth and finely lineated seed surface $C$. album. On the basis of surface features of their seeds, $C$. quinoa was suggested to be more closely related to $C$. berlandieri than to $C$. album. Besides the black and brown seeds observed in different accessions of $C$. album, we also observed white seeds in two accessions viz. IC-411824 and IC-411825, which have been identified by National Bureau of Plant Genetic Resources, India as C. album but have foveate type pollen grains, dull texture of seeds with a smooth surface which is typical of C. quinoa. Baar [27], who made the first attempt to describe seed heterogeneity in $C$. album, has reported the presence of both black and brown seeds within the same plant. Many others have, however, postulated the existence of cryptic heterospermy manifested by the presence of black seeds of various sizes and of their capability for rapid or delayed germination in C. album [28,29,30,31,32].

Even though seed coat morphology has been used as a phenotypic character in species identification in the genus Chenopodium [32,33], the existence of heteromorphs in different species of the genus, especially $C$. album, necessitates the use of other characters including molecular markers in taxonomic identification in this genus. SDS-PAGE profiles of seed proteins from the 19 accessions belonging to $C$. quinoa and $C$. album revealed a maximum of 22 bands in an accession with molecular weight ranging from 26-68 $\mathrm{kDa}$ out of which 6 were monomorphic and 16 were polymorphic in nature (Fig. 1). While seven bands representing proteins having molecular weights 68.7, 58.59, 55.85, $48.40,46.14,41.27$ and $37.51 \mathrm{kDa}$ were detected in all eleven exotic accessions belonging to $C$. quinoa viz. EC-507738, EC507739, EC-507739-1, EC-507740, EC-5077401, EC-5077402, EC-507741, E-C507742, EC-507744, EC-507747, EC-507748 and 
Table 1: Accessions of Chenopodium quinoa and Chenopodium album studied in the present investigation. Variations observed in the morphological parameters are listed. Parameters codes: A-Leaf color, B-Leaf shape, C-Leaf apex, D-Leaf margin, E-Seed color, F-Seed texture, G-Seed coat, H-Seed edge and I-pollen

\begin{tabular}{|c|c|c|c|c|c|c|c|c|c|c|c|}
\hline $\begin{array}{l}\text { Sl. } \\
\text { no. }\end{array}$ & Accessions & Species & $\mathbf{A}$ & B & $\mathbf{C}$ & D & $\mathbf{E}$ & $\mathbf{F}$ & $\mathbf{G}$ & $\mathbf{H}$ & I \\
\hline 1 & EC507738 & C. quinoa & Green & Rhombic & Acute & Dentate & White & Dull & Smooth & Smooth & Foveate \\
\hline 2 & EC507739 & C. quinoa & Green & Rhombic & Acute & Dentate & White & Dull & Smooth & Smooth & Foveate \\
\hline 3 & EC5077391 & C. quinoa & Green & Rhombic & Acute & Dentate & White & Dull & Smooth & Smooth & Foveate \\
\hline 4 & EC507740 & C. quinoa & Green & Rhombic & Acute & Dentate & White & Dull & Smooth & Smooth & Foveate \\
\hline 5 & EC5077401 & C. quinoa & Green & Rhombic & Acute & Dentate & White & Dull & Smooth & Smooth & Foveate \\
\hline 6 & EC5077402 & C. quinoa & Green & Rhombic & Acute & Dentate & White & Dull & Smooth & Smooth & Foveate \\
\hline 7 & EC507741 & C. quinoa & Green & Rhombic & Acute & Dentate & White & Dull & Smooth & Smooth & Foveate \\
\hline 8 & EC507742 & C. quinoa & Green & Rhombic & Acute & Dentate & White & Dull & Smooth & Smooth & Foveate \\
\hline 9 & EC507744 & C. quinoa & Green & Rhombic & Acute & Dentate & White & Dull & Smooth & Smooth & Foveate \\
\hline 10 & EC507747 & C. quinoa & Green & Rhombic & Acute & Entire & White & Dull & Smooth & Smooth & Foveate \\
\hline 11 & EC507748 & C. quinoa & Green & Rhombic & Acute & Dentate & White & Dull & Smooth & Smooth & Foveate \\
\hline 12 & IC411824 & C. album & Green & Rhombic & Acute & Dentate & White & Dull & Smooth & Smooth & Foveate \\
\hline 13 & IC411825 & C. album & Green & Rhombic & Acute & Dentate & White & Dull & Smooth & Smooth & Foveate \\
\hline 14 & IC341704 & C. album & Green & Lanceolate & Obtuse & Entire & Black & Shiny & Reticulate & Pattern & Perforate \\
\hline 15 & NIC22517 & C. album & Red & Rhombic & Acute & Dentate & Black & Shiny & Smooth & Pattern & Perforate \\
\hline 16 & IC341700 & C. album & Red & Rhombic & Acute & Dentate & Black & Shiny & Reticulate & Pattern & Perforate \\
\hline 17 & IC447575 & C. album & Red & Rhombic & Acute & Dentate & Brown & Shiny & Smooth & Smooth & Perforate \\
\hline 18 & EC359447 & C. album & Red & Rhombic & Acute & Dentate & Black & Shiny & Smooth & Pattern & Perforate \\
\hline 19 & EC359451 & C. album & Red & Rhombic & Acute & Dentate & Black & Shiny & Smooth & Pattern & Perforate \\
\hline
\end{tabular}

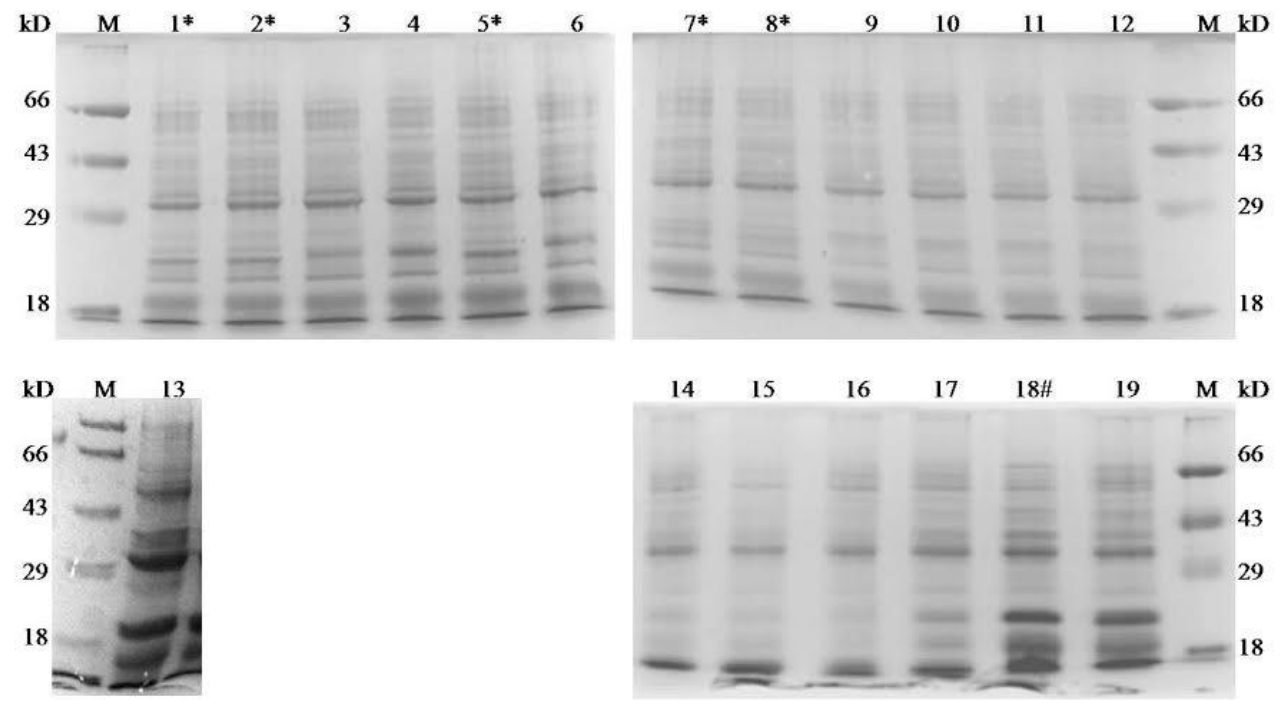

Fig. 1: SDS-PAGE profile of soluble seed proteins extracted from different accessions of Chenopodium quinoa and C. album investigated in the present study. (1) EC-507744, (2) EC-507742, (3) IC-411825, (4) IC-411824, (5) EC-507738, (6) EC-507739, (7) EC-5077391, (8) EC-507741, (9) EC-5077401, (10) EC5077402, (11) EC-507740, (12) EC-507748, (13) EC-507747, (14) EC-359447, (15) IC-447575, (16) IC-341700, (17) NIC-22517, (18) IC341704. (19) EC359451. While '*' indicates five accessions of C. quinoa detected with the duplex of 33.55 and $29.59 \mathrm{kDa}$ protein bands, '\#' indicates the accession IC-341704 of C. album with one protein band of molecular mass $35.76 \mathrm{kDa}$. M: standard molecular weight markers.

two accessions viz. IC-411824 and IC-411825 identified as $C$. album, five bands representing proteins having molecular mass of $67.62,60.48,54.97,50.76$ and $36.91 \mathrm{kDa}$ were detected only in six accessions viz. IC-341704, NIC-22517, IC-341700, IC-447575, EC-359447, EC-359451 which belong to C. album.

An important feature of the profile was the presence of one band representing protein with molecular mass of $35.76 \mathrm{kDa}$ in IC-341704 of C. album. This protein band was not detected in any other accession investigated in the present study. The accession IC-341704 has lanceolate shaped leaves with an obtuse apex and entire margin whereas all the other accessions have rhombic shaped leaves with an acute apex and dentate margins.
Another important feature of the profiles was the detection of a duplex of 33.55 and $29.59 \mathrm{kDa}$ protein bands in five accessions of C. quinoa viz. EC-507744, EC-507742, EC-507738, EC-5077391 and EC-507741. This duplex could not be detected in any other accession of Chenopodium studied in the present investigation. Fairbanks et al. [34] have reported the presence of three polymorphic polypeptides having molecular masses of 34.3, 35.6 and $36.2 \mathrm{kDa}$ from the globulin fraction of seed proteins of $C$. quinoa. On the other hand Bhargava et al. [35] have reported 72 bands from 40 species of Chenopodium and Drzewiecki et al. [36] have reported 41 protein bands in SDS-PAGE profiles of seed proteins of $C$. quinoa. 


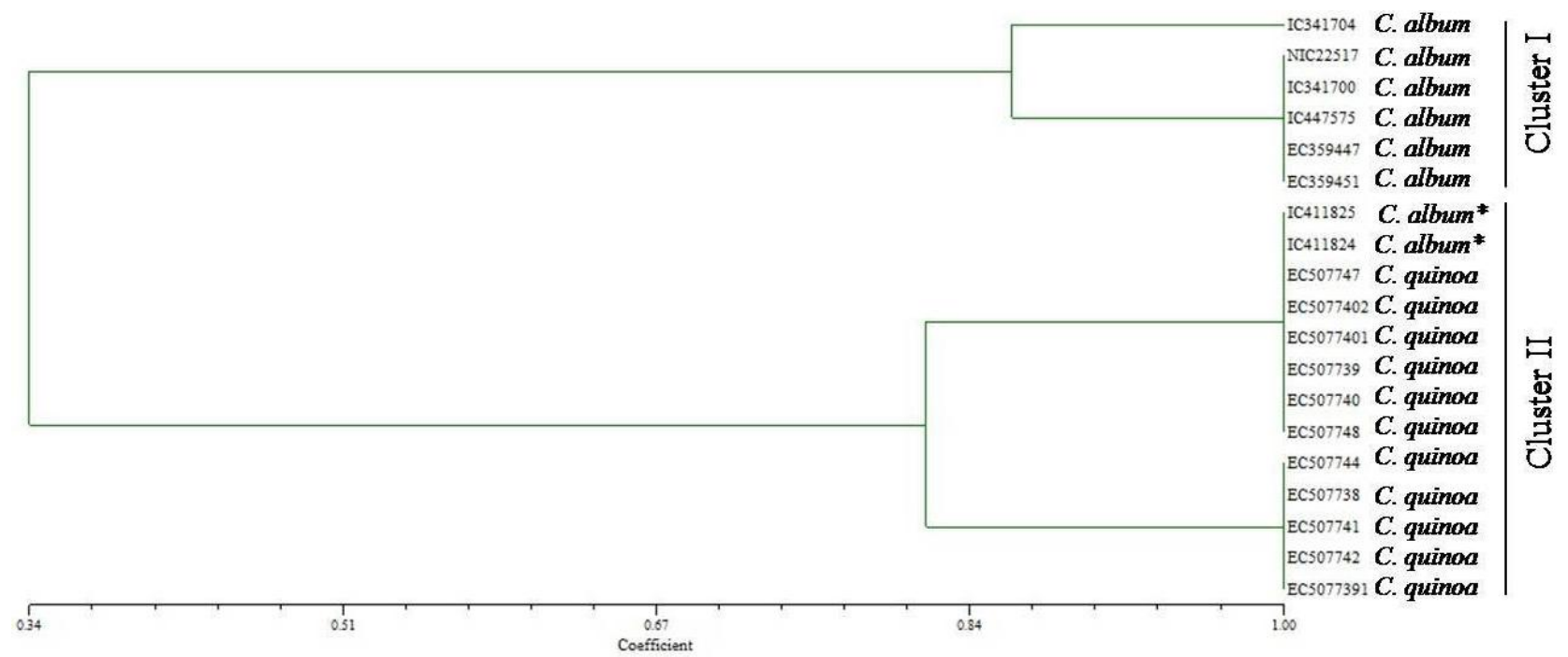

Fig. 2: Dendrogram generated on the basis of UPGMA (Unweighted Pair Group Method with Arithmetic Mean) analysis of the similarity matrix of SDS-PAGE profiles of soluble seed proteins of different accessions of Chenopodium studied in the present investigation. *Two accessions identified as $C$. album by NBPGR grouped together with C. quinoa. Numbers prefixed with IC/ EC/NIC indicates the accession numbers of the plants.

The difference in the number of proteins detected could be ascribed to the differences in the composition of the extraction buffers. While Drzewiecki et al. [36] focused on profiling of total seed proteome, our investigation focused only on the soluble seed proteins.

Statistical analysis of the SDS-PAGE profile revealed an average polymorphic Information Content (PIC) value of 0.42 (Fig. 2). The UPGMA dendrogram generated from the similarity matrix of binary data of SDS-PAGE profiles resolved the accessions of chenopods into two broad clusters wherein C. album grouped as Cluster I and $C$. quinoa grouped as Cluster II with inter cluster Jaccard's similarity co-efficient value of 0.34 . These results are in conformity with the observations of Bhargava et al. [35] who have also reported the segregation of $C$. quinoa and C. album into two clusters on the basis of their seed protein electrophoretic profiles. The accession IC-341704 of C. album emerged as a separate clade in cluster I with a similarity co-efficient value 0.84 with other five accessions of $C$. album that clustered together as another clade with a similarity co-efficient value of 1.0 in cluster I. Two accessions viz. IC-411824 and IC-411825 of C. album, which have white coloured seeds, clustered together with other accessions in one of the clades of Cluster II. Cluster II segregated into two sub-clusters wherein each sub-cluster showed a similarity co-efficient value of 1.0 and the two sub-clusters showed an inter cluster similarity coefficient of 0.78 . Wilson [37], Raus et al. [19] and Bhargava et al. [35] have also reported a low level of variation in allozyme, RAPD and seed protein profiles amongst the accessions of $C$. quinoa. While Bhargava et al. [35] have suggested $C$. album to be a heterogeneous assemblage of species, our results on SDS-PAGE profiles of soluble seed proteins indicate a high level of genetic similarity amongst the accessions of $C$. album except IC-341704. It is possible that the "heterogeneous assemblage of species" as observed by Bhargava et al. [35] may be actually an assemblage of "cytotypes" in
C. album. While Bhargava et al. [35] had investigated the SDSPAGE profiles of seed proteins in three cytotypes $(2 n=18,4 n=36$, $6 \mathrm{n}=54$ ), all the accessions of $C$. album, except IC-411824 and IC411825 , studied in the present investigation were hexaploid $(6 n=54)$. The accessions IC-411824 and IC-411825 were tetraploid $(2 n=36)$.

These observations clearly indicate a relationship between heteromorphy and ploidy level in accessions of C. album. Our observations also suggest the accessions IC-411824 and IC411825 to be $C$. quinoa rather than C. album.

\section{CONCLUSIONS}

The work establishes the identity of accessions IC411824 and IC-411825 as C. quinoa rather than C. album. Our observations also indicate a relationship between ploidy level and heteromorphy in C. album.

\section{ACKNOWLEDGMENTS}

Financial support received from Department of Biotechnology, Govt. of India vide Grant no. BT/PR8953/BCE/08/533/2007 and Grant no BT/04/NE/2009 under the Biotech Hub programme is gratefully acknowledged. RJD gratefully acknowledges the receipt of financial support from Department of Science \& Technology, Govt. of India in the form of a research fellowship under the INSPIRE.

\section{REFERENCES}

1. Kühn U. Chenopodiaceae. In: Kubitzki, K. (Ed) The families and genera of vascular plants, Springer, Hamburg; 1993, p 253-281.

2. Bhargava A, Shukla S, Srivastava J, Singh N, Ohri D. Genetic diversity for mineral accumulation in the foliage of Chenopodium spp. Sci Hortic. 2008; 118: 338-346.

3. Koziol MJ. Chemical composition and nutritional value of quinoa (Chenopodium quinoa Willd.). J Food Compost Anal. 1992; 5: 3568. 
4. Ruales J, Nair BM. Nutritional quality of the protein in quinoa (Chenopodium quinoa, willd) seeds. Plant Foods Hum Nutr. 1992; 42:1-11.

5. Wilson H, Manhart J. Crop/weed gene flow: Chenopodium quinoa Willd. and C. berlandieri Moq. Theor Appl Genet. 1993; 86: 642648

6. Bhargava A, Shukla S, Ohri D. Karyotypic studies on some cultivated and wild species of Chenopodium (chenopodiaceae). Genet Resour Crop Ev. 2006; 53: 1309-1320.

7. Kolano B, Siwińska D, Małuszyńska J. Comparative cytogenetic analysis of diploid and hexaploid Chenopodium album Agg. Acta Soc Bot Pol. 2008; 77: 293-298.

8. Fuentes-Bazan S, Mansion G, Borsch T (2012) Towards a species level tree of the globally diverse genus Chenopodium (Chenopodiaceae). Mol Phylogenet Evol 62: 359-374.

9. Wilson HD. Quinoa and relatives (Chenopodium sect. Chenopodium subsect. Cellulata). Econ Bot. 1990; 44: 92-110.

10. Wilson HD. Artificial Hybridization among Species of Chenopodium sect. Chenopodium. Syst Botany. 1980; 5: 253-263.

11. Gangopadhyay G, Das S, Makhwrjee KK. Speciation in Chenopodium in west Bengal, India. Genet Resour Crop Evol. 2002; 49: 503-510.

12. Anderson WR. Genetic relationships among 19 accessions of six species of Chenopodium L. by random amplified polymorphic DNA fragments (RAPD). Euphytica. 1999; 105: 25-32.

13. Rana TS, Narzary D, Ohri D. Genetic diversity and relationships among some wild and cultivated species of Chenopodium L. (Amaranthaceae) using RAPD and DAMD methods. Curr Sci. 2010; 98: 840-846.

14. Mason SL, Stevens MR, Jellen EN, Bonifacio A, Fairbanks DJ, Coleman CE, McCarty RR, Rasmussen AG, Maughan PJ. Development and use of microsatellite markers for germplasm characterization in quinoa (Chenopodium quinoa Willd.). Crop Sci. 2005; 45:1618-1630.

15. Maughan PJ, Kolano BA, Maluszynska J, Coles ND, Bonifacio A, Rojas J, Coleman CE, Stevens MR, Fairbanks DJ, Parkinson SE, Jellen EN. Molecular and cytological characterization of ribosomal RNA genes in Chenopodium quinoa and Chenopodium berlandieri. Genome. 2006; 49: 825-839.

16. Mehra P, Malik C. Cytology of some Indian Chenopodiaceae. Caryologia. 1963; 16: 67-84.

17. Mukherjee KK. A comparative study of two cytotypes of Chenopodium album in West Bengal, India. Can J Bot. 1986; 64: 754-759.

18. Rahiminejad MR, Gornall RJ. Flavonoid evidence for allopolyploidy in the Chenopodium album aggregate (Amaranthaceae). Plant Syst Evol. 2004; 246: 77-87.

19. Ruas PM, Bonifacio A, Ruas CF, Fairbanks DJ, Andersen WR. Genetic relationships among 19 accessions of six species of Chenopodium L. by random amplified polymorphic DNA fragments (RAPD). Euphytica. 1999; 105:25-32.

20. Rana TS, Narzary D, Ohri D. Molecular differentiation of Chenopodium album complex and some related species using ISSR profiles and ITS sequences. Gene. 2011; 495: 29-35.

21. Clements SE, Mosyakin SL. Flora of North America Volume 4: Magnoliophyta: Caryophyllidae, Part 1, Chenopodiaceae, Chenopodium. Oxford University Press, Toronto; 2004.

22. Partap T, Kapoor P The Himalayan grain Chenopods 11. Comparative morphology. Agric Ecosyst Environ. 1985; 14: 201-220.
23. Bradford MM. A rapid and sensitive $m$ ethod for the quantification of micrograms of protein utilizing the principle dye binding. Anal Biochem. 1976; 72: 248-254.

24. Laemmli UK. Cleavage of structural proteins during the assembly of the head of bacteriophage T4. Nature. 1970; 227: 680-685.

25. Bhargava A, Shukla S, Ohri D. Evaluation of foliage yield and leaf quality traits in Chenopodium spp. in multiyear trials. Euphytica. 2007a; 153: 199-213.

26. Karcz J, Kolano B, Maluszynska J. SEM studies on fruit and seed of some Chenopodium L. species (Chenopodiaceae). XII International Conference on Plant Embryology, Cracow, Poland; 2005.

27. Baar H. Zur Anatomie und Keimungsphysiologie heteromorpher Samen von Chenopodium album and Atriplex nitens. Sitzungsber Kaiserl Akad Wiss Wien. 1913; 121: 21-40.

28. Williams JT, Harper JL. Seed dimorphism and germination. I. The influence of nitrates and low temperatures on the germination of Chenopodium album. Weed Res. 1965; 5: 141-150.

29. Harper JL. Population biology of plants. London: Academic Press; 1977.

30. Roberts HA, Neilson JE. Seed survival and periodicity of seedling emergence in some species of Atriplex, Chenopodium, Polygonum and Rumex. Ann Appl Biol. 1980; 94: 111-120.

31. Kamayeva GM. Heterocarpy and heterospermy of the weedy Chenopodium and Atriplex occurring in Voronezh province. In: Khmelyov KF (Eds) Vegetation of the Black Earth Region and its protection, Voronezh University Press; 1987, p 57-62.

32. Matilla A, Gallardo M, Puga-Hermida MI. Structural, physiological and molecular aspects of heterogeneity in seeds: Areview. Seed Sci Res. 2005; 15: 63-76.

33. Yao S, Lan $\mathrm{H}$, Zhang $\mathrm{F}$. Variation of seed heteromorphism in Chenopodium album and the effect of salinity stress on the descendants. Ann Bot. 2010; 105: 1015-1025.

34. Fairbanks DJ, Burgener KW, Robison LR, Andersen WR, Ballon E. Electrophoretic characterization of quinoa seed proteins. Plant Breed. 1990; 104: 190-195.

35. Bhargava A, Rana TS, Shukla S, Ohri D. Seed protein electrophoresis of some cultivated and wild species of Chenopodium (Chenopodiaceae). Biol Plant. 2005; 49: 505-511.

36. Drzewiecki J, Delgado-Licon E, Haruenkit A. Identification and Differences of Total Proteins and Their Soluble Fractions in Some Pseudocereals Based on Electrophoretic Patterns. J Agri Food Chem. 2003; 51: 7798-7804.

37. Wilson HD. Allozyme variation and morphological relationships of Chenopodium hircinum (sl). Syst Botany. 1988; 215-228.

\section{How to cite this article:}

Devi RJ and Chrungoo NK. Species relationships in Chenopodium quinoa and Chenopodium album on the basis of morphology and SDS-PAGE profiles of soluble seed proteins. J App Biol Biotech, 2015; 3 (06): 029-033. DOI: 10.7324/JABB.2015.3605 